EXTENDED REPORT

\title{
Correlation and sex differences between ankle and knee cartilage morphology determined by quantitative magnetic resonance imaging
}

\author{
F Eckstein, V Siedek, C Glaser, D Al-Ali, K-H Englmeier, M Reiser, H Graichen
}

Ann Rheum Dis 2004;63:1490-1495. doi: 10.1136/ard.2003.018226

See end of article for authors' affiliations

Correspondence to: Professor Felix Eckstein, Institute of Anatomy and Musculoskeletal Research PMU, Strubergasse 21, A5020 Salzburg, Austria; felix.eckstein@pmu.ac.at

Accepted 27 January 2004

\begin{abstract}
Objective : To study the correlation between ankle and knee cartilage morphology to test the hypothesis that knee joint cartilage loss in gonarthritis can be estimated retrospectively using quantitative MRI analysis of the knee and ankle and established regression equations; and to test the hypothesis that sex differences in joint surface area are larger in the knee than the ankle, which may explain the greater incidence of knee osteoarthritis in elderly women than in elderly men.

Methods : Sagittal MR images (3D FLASH WE) of the knee and hind foot were acquired in 29 healthy subjects ( 14 women, 15 men; mean (SD) age, 25 (3) years), with no signs joint disease. Cartilage volume, thickness, and joint surface area were determined in the knee, ankle, and subtalar joint.

Results: Knee cartilage volumes and joint surface areas showed only moderate correlations with those of the ankle and subtalar joint ( $r=0.33$ to 0.81 ). The correlations of cartilage thickness between the two joints were weaker still ( $r=-0.05$ to 0.53 ). Sex differences in cartilage morphology at the knee and the ankle were similar, with surface areas being $-17.5 \%$ to $-23.5 \%$ lower in women than in men.

Conclusions: Only moderate correlations in cartilage morphology of healthy subjects were found between knee and ankle. It is therefore impractical to estimate knee joint cartilage loss a posteriori in cross sectional studies by measuring the hind foot and then applying a scaling factor. Sex differences in cartilage morphology do not explain differences in osteoarthritis incidence between men and women in the knee and ankle.
\end{abstract}

M agnetic resonance (MR) imaging based measurements of cartilage morphology are being used increasingly as a quantitative end point of disease status and a marker of disease progression in osteoarthritis. ${ }^{1-3}$ This technique can be employed either to measure structural changes in the joint longitudinally ${ }^{3-5}$ or to grade cartilage status in cross sectional studies, ${ }^{267}$ for instance at the onset of symptomatic osteoarthritis. Accurate retrospective estimates of cartilage loss are also important when determining the appropriate time point and type of treatment for patients with osteoarthritis, in carrying out cross sectional epidemiological studies, or when selecting specific patient groups for longitudinal trials. However, one problem with such retrospective estimates is the relatively large intersubject variability of normal (healthy) cartilage morphology. ${ }^{6-9}$ Also there is a lack of strong correlation with anthropometric factors such as age, body height and weight, and muscle cross sectional area. ${ }^{710}$ These two factors render the retrospective estimate of the "original" cartilage volume (before the onset of disease) and of the amount of cartilage loss (original cartilage volume minus currently measured cartilage volume) a diagnostic and scientific challenge. ${ }^{7}$

It has been shown previously that differences in cartilage volume, thickness, and surfaces area in healthy contralateral knees are relatively small. ${ }^{11}$ Thus in a case of unilateral osteoarthritis it may be feasible to estimate the original cartilage morphology from the contralateral (unaffected) joint. However, strictly unilateral knee osteoarthritis is rare, and early morphological changes in the contralateral knee are difficult to rule out with certainty.

Another possible approach to resolve this challenge is to measure a cartilage plate in another joint which is less often affected by primary osteoarthritis, such as the ankle. ${ }^{12-14}$ If a strong correlation of cartilage morphology between the knee and ankle can be established in healthy subjects, and if osteoarthritic changes in the ankle are not associated with osteoarthritic changes in the knee, it may be possible (a) to estimate the original cartilage volume (before osteoarthritis) in the knee by measuring cartilage volume in a healthy ankle and applying a scaling factor based on an established regression equation (fig 1 ); and (b) to estimate tissue loss by subtracting the current measured cartilage volume in the knee (with osteoarthritis) from the estimated original cartilage volume (before osteoarthritis), as described in (a).

As mentioned previously, the potential for these estimates to be useful is dependent on a strong correlation between knee and ankle cartilage volume in health. The stronger the correlation coefficient and the narrower the standard error of the estimate between knee and ankle cartilage morphology, the more precise the estimate. Our primary objective in this study was thus to examine the association between cartilage morphology in the healthy knee and ankle (fig 1). The ankle (and subtalar) joints were selected for the following reasons: first, they show much lower susceptibility to and severity of osteoarthritis than the knee ${ }^{12-14}$; second, they represent lower limb joints that encounter similar loading profiles to the knee; third, they can be imaged using a circumferential coil with high signal homogeneity and a high contrast to noise ratio; and fourth, they allow for quantitative measurements of cartilage indices with satisfactory reproducibility (precision) in vivo. ${ }^{15}$

The second objective of this study was to investigate sex differences in quantitative cartilage indices at the ankle and

Abbreviations: $\mathrm{BCl}$, bone-cartilage interface; $\mathrm{FLASH}$, fast low angle shot; JSA, joint surface area; MR(I), magnetic resonance (imaging) 


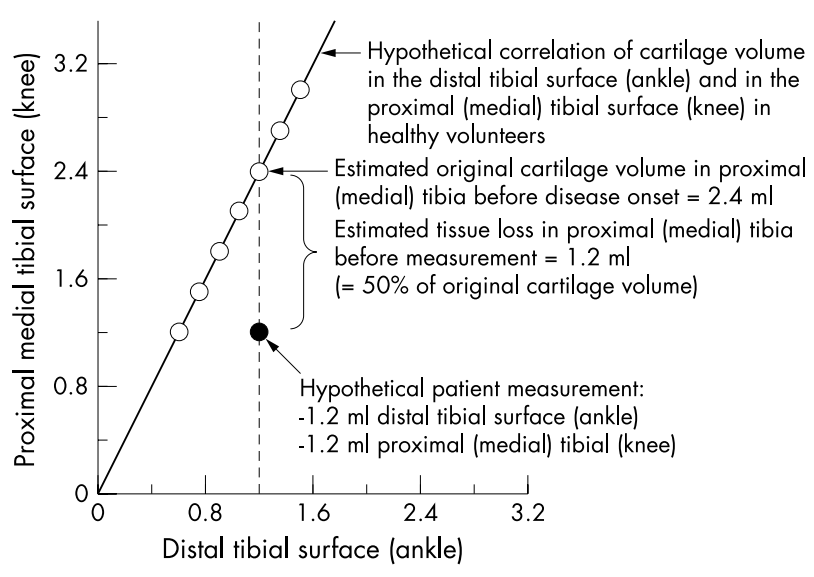

Figure 1 Scattergram showing the rationale for the study. If the hypothesis is correct that there is a strong linear relation between knee joint cartilage volume in the knee and ankle surfaces (for example, medial tibia and distal tibia) in healthy volunteers (empty circles), this relation can be exploited to estimate retrospectively the amount of tissue loss in the knee surface in a cross sectional study. In the 29 healthy volunteers examined in this study, the cartilage volume of the medial tibia (knee joint) varied from 1.1 to $3.2 \mathrm{ml}$ (mean $2.3 \mathrm{ml}$ ), and that of the distal tibia (ankle joint) from 0.6 to $1.7 \mathrm{ml}$ (mean $1.1 \mathrm{ml}$ ). The graph also shows the hypothetical measurement in a patient (filled circle). Assuming a strong linear relation in healthy volunteers (empty circles), one could accurately estimate the cartilage tissue loss in the medial tibia of the hypothetical patient to amount to $1.2 \mathrm{ml}$ (50\% cartilage loss), although the measurement at the knee of this patients falls within the normal range.

knee. Although women over the age of 50 show a higher incidence of knee osteoarthritis than men of the same age, ${ }^{16}$ osteoarthritis of the ankle is somewhat more frequent in men. ${ }^{14}$ It has been speculated that differences in accrual of knee cartilage during adolescence may be responsible for sex differences in susceptibility to knee osteoarthritis later in life. ${ }^{17} 18$ It has also been reported that, in the knee, sex differences in joint surfaces area are larger than those of cartilage thickness. ${ }^{19}$ We therefore tested the hypothesis that sex differences in knee cartilage morphology are larger than those in the ankle and subtalar joints, potentially explaining the higher incidence of knee osteoarthritis in elderly women.

\section{METHODS}

\section{Study subjects}

We examined 29 healthy volunteers with no history of knee or ankle pain, trauma, surgery, or ligament or meniscal lesions. Fourteen of the subjects were women (mean (SD) age, 25.0 (4.2) years), and 15 were men (age 24.7 (2.1) years). The men were significantly taller (180 (4.8) $v 167$ (7.8) $\mathrm{cm} ; \mathrm{p}<0.001$ ) and heavier (72.6 (7.1) v 59.0 (6.4) kg; $\mathrm{p}<0.001)$ than the women, but the mean body mass index was similar (22.4 (2.2) v $\left.21.4(3.8) \mathrm{kg} / \mathrm{m}^{2}\right)$. Informed written consent was obtained from each subject, and the consent form and study protocol were ratified by the local ethic committee.

\section{MR image acquisition and analysis}

Imaging was carried out with a $1.5 \mathrm{~T}$ MR scanner (Magnetom Vision, Siemens, Erlangen, Germany) and a circularly polarised transmit-receive extremity coil. A sagittal Tl weighted 3D FLASH (fast low angle shot) MR sequence with selective water excitation (RF amplitude ratios $1-2-1$; time of repetition $(\mathrm{TR})=18 \mathrm{~ms}$, time of echo $(\mathrm{TE})=9 \mathrm{~ms}$; flip angle $(F A)=25$, band width $=105 \mathrm{~Hz} /$ pixel) was used for the hind foot $^{15}$ (resolution $1 \times 0.25 \times 0.25 \mathrm{~mm}$; field of view $(\mathrm{FOV})=12 \mathrm{~cm}$; matrix $=512 \times 512$; number of excitations $(\mathrm{NEX})=2$; acquisition time $=19$ minutes $)$ and a similar sequence $(\mathrm{TR}=17.2 \mathrm{~ms}, \mathrm{TE}=6.6 \mathrm{~ms} ; \mathrm{FA}=25)$ for the knee joint ${ }^{20}$ (resolution $1.5 \times 0.31 \times 0.31 \mathrm{~mm} ; \mathrm{FOV}=16 \mathrm{~cm}$, matrix $=512 \times 512 ; \mathrm{NEX}=1$, acquisition time $=9$ minutes $)$ (fig 2). These MR sequences have previously been shown to yield accurate (valid) results for quantitative indices of cartilage morphology in the knee joints of healthy volunteers, ${ }^{20}$ in patients with severe osteoarthritis, ${ }^{21}$ and in joints with thin cartilage. ${ }^{22}{ }^{23}$ In 16 volunteers (eight women, eight men) additional axial spin echo images at the thigh (at 50\% of the distance between the greater trochanter and knee joint space) and at the maximum circumference of the calf) were acquired to determine muscle cross sectional areas at these locations. ${ }^{11}$

An Octane Duo work station (Silicon Graphics Inc, Mountain View, California, USA) was used for digital image analysis. A semiautomated B-spline Snake algorithm was employed for segmentation of the distal tibial and proximal talar cartilage plate (ankle joint), the distal talar and

Table 1 Correlation coefficients ( $r$, Pearson) between the knee, ankle, and subtalar joint surfaces

\begin{tabular}{|c|c|c|c|c|c|c|c|c|}
\hline & & Medial tibia & Lateral tibia & Femur & Distal tibia & Proximal talus & Distal talus & Calcaneus \\
\hline \multirow[t]{3}{*}{ Patella } & Volume & $0.66^{* *}$ & $0.73^{\star *}$ & $0.77^{* *}$ & 0.33 & $0.41^{*}$ & $0.44^{*}$ & 0.34 \\
\hline & Thickness & $0.54^{*}$ & $0.65^{\star *}$ & $0.48^{*}$ & 0.05 & -0.05 & 0.11 & 0.10 \\
\hline & JSA & $0.65^{* *}$ & $0.72^{* *}$ & $0.82^{\star *}$ & $0.76^{* *}$ & $0.61^{* *}$ & $0.73^{* *}$ & $0.61^{\star *}$ \\
\hline \multirow[t]{3}{*}{ Medial tibia } & Volume & & $0.72^{* *}$ & $0.89 * *$ & $0.67^{* *}$ & $0.71^{* *}$ & $0.70^{* *}$ & $0.66^{* *}$ \\
\hline & Thickness & & $0.78^{\star *}$ & $0.86^{* *}$ & $0.46^{*}$ & 0.36 & $0.51^{* *}$ & $0.46^{*}$ \\
\hline & JSA & & $0.70^{* *}$ & $0.73^{* *}$ & $0.71^{\text {** }}$ & $0.68^{* *}$ & $0.69^{* *}$ & $0.62^{* *}$ \\
\hline \multirow[t]{3}{*}{ Lateral tibia } & Volume & & & $0.87^{* *}$ & $0.40^{*}$ & $0.59^{* *}$ & $0.60^{* *}$ & $0.55^{\star *}$ \\
\hline & Thickness & & & $0.77^{* *}$ & 0.03 & -0.11 & 0.10 & 0.20 \\
\hline & JSA & & & $0.89^{* *}$ & $0.71^{\text {** }}$ & $0.71^{\star *}$ & $0.73^{* *}$ & $0.72^{* *}$ \\
\hline \multirow[t]{3}{*}{ Femur } & Volume & & & & $0.60^{* *}$ & $0.81^{* *}$ & $0.72^{* *}$ & $0.68^{* *}$ \\
\hline & Thickness & & & & 0.30 & 0.29 & $0.53^{*}$ & $0.52^{* *}$ \\
\hline & JSA & & & & $0.85^{\star *}$ & $0.75^{\star \star}$ & $0.77^{* *}$ & $0.71^{* *}$ \\
\hline \multirow{3}{*}{ Distal tibia } & Volume & & & & & $0.81^{* *}$ & $0.77^{* *}$ & $0.77^{* *}$ \\
\hline & Thickness & & & & & $0.87^{* *}$ & $0.63^{* *}$ & $0.42^{*}$ \\
\hline & JSA & & & & & $0.74^{* *}$ & $0.86^{* *}$ & $0.79^{* *}$ \\
\hline \multirow[t]{3}{*}{ Proximal talus } & Volume & & & & & & $0.80^{* *}$ & $0.77^{\star *}$ \\
\hline & Thickness & & & & & & $0.70^{* *}$ & $0.42^{*}$ \\
\hline & JSA & & & & & & $0.75^{\text {** }}$ & $0.63^{* *}$ \\
\hline \multirow[t]{3}{*}{ Distal talus } & Volume & & & & & & & $0.95^{\star *}$ \\
\hline & Thickness & & & & & & & $0.74^{* *}$ \\
\hline & JSA & & & & & & & $0.93^{\star *}$ \\
\hline
\end{tabular}

JSA, joint surface area $\left(\mathrm{cm}^{2}\right)$; thickness, mean cartilage thickness $(\mathrm{mm})$; volume, cartilage volume (ml).

${ }^{*} \mathrm{p}<0.05,{ }^{* *} \mathrm{p}<0.01$ 

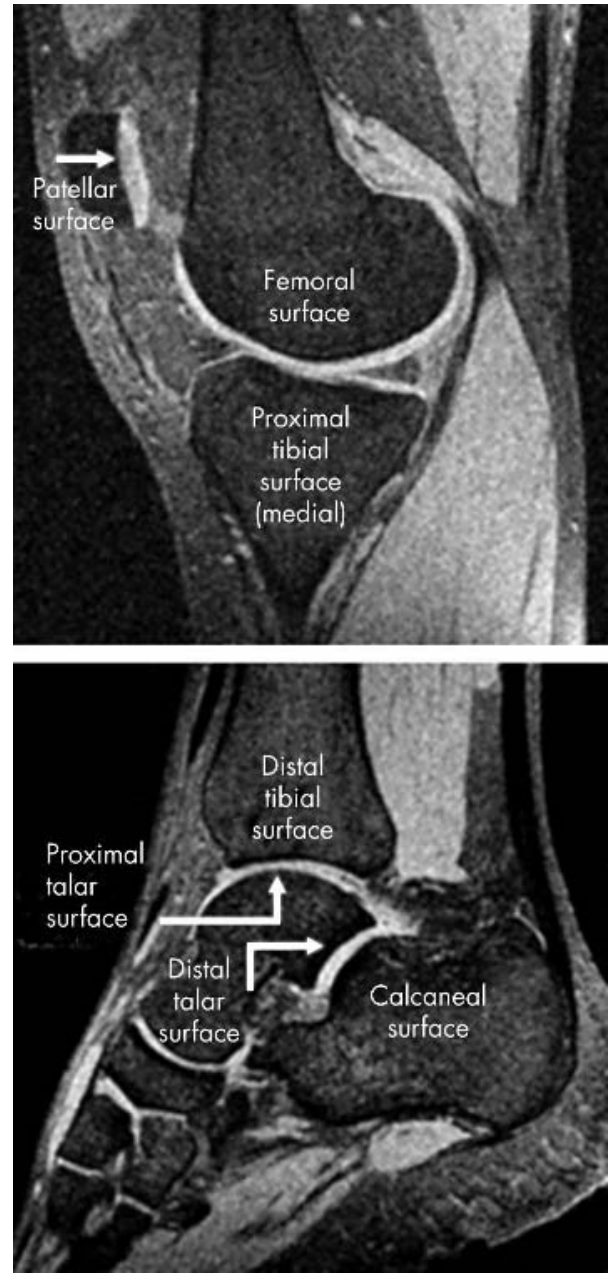

Figure 2 Sagittal magnetic resonance images of the knee and ankle, acquired with a high resolution FLASH (fast low angle shot) wider excitation sequence. The figure also displays the surfaces that have been analysed in the current study.

calcaneal cartilage plate (subtalar joint), and the patellar, femoral, and proximal tibial cartilage plates (knee joint). ${ }^{24}$ The cartilage volume of each plate was determined by numerical integration of the attributed voxels, ${ }^{25}$ and the size of the joint surface area (JSA) and bone-cartilage interface (BCI) with a validated triangulation algorithm. ${ }^{26}$ The mean and maximum cartilage thickness were determined, independent of the original section orientation, using three dimensional Euclidean distance transformation. ${ }^{27}$ The total cartilage volume and surface areas in the ankle, subtalar, and knee joints were obtained by summing the surfaces within each joint. The mean cartilage thickness was computed by weighting the mean thicknesses of the relevant joint surfaces with their relative proportion of the total joint surface area. ${ }^{8}{ }^{15}$ The in vivo reproducibility of the imaging protocols and analysis steps have been reported previously. ${ }^{15} 28$ Test-retest precision errors (with joint repositioning) ranged from $2.0 \%$ to $3.6 \%(\mathrm{CV} \%)$ in the knee, and from $2.1 \%$ to $8.1 \%$ in the ankle and subtalar joint. The muscle cross sectional areas (MCSAs) of the thigh (quadriceps, adductors, and flexors) and calf (mainly triceps surae) were determined with the same segmentation tool, ${ }^{24}$ and subcutaneous fat, muscle septs with adipose tissue, and bones were eliminated from the analysis. The area was again determined by numerical integration of segmented voxels, and the precision for these measurements has been reported previously. ${ }^{10}$

\section{Statistical analysis}

The correlation between the ankle, subtalar, and knee joint surfaces, and the muscle cross sectional areas of the thigh and calf were determined by linear regression analysis (Pearson correlation coefficient and standard error of the estimate). Average correlation coefficients within the knee joint surfaces, within the hind foot cartilage plates, and between the knee and hind foot plates were determined by computing the means of correlation coefficients. Coefficients were compared in order to identify possible significant differences, using the Fisher $z$ test. Sex differences were tested for statistical significance using an unpaired $t$ test.

\section{RESULTS}

The cartilage volumes and joint surface areas of the knee showed only moderate correlations with those of the ankle and subtalar joint $(r=0.33$ to 0.81 ; table 1$)$. The correlation of mean cartilage thickness between the knee and ankle was weaker still $(r=-0.05$ to 0.53 ; table 1$)$. Correlation coefficients between cartilage volumes of the knee and body height ranged from $r=0.54$ (patella) to $r=0.79$ (femur), and those for the ankle from $r=0.44$ (calcaneus) to $r=0.5 \mathrm{l}$ (proximal talus). Correlation coefficients between cartilage thickness and body height were again lower and ranged from $r=0.05$ (patella) to $r=0.64$ (femur) in the knee, and from $r=0.17$ (distal tibia) to $r=0.31$ (distal talus) in the ankle.

The correlation of morphological indices among joint cartilage plates of the same joint (for example, within the knee) was stronger than that between cartilage plates of different joints (between knee and ankle) (table 2). The associations between the ankle and subtalar joint plates tended to be stronger than those between the ankle and knee joint and between and subtalar and knee joint, respectively. The correlation was generally stronger for joint surface areas (and cartilage volumes) than for cartilage thickness (table 1). The associations of cartilage volume, cartilage thickness, and surface area between the (total) knee, ankle, and subtalar joint are shown in fig 3. The standard error of the estimate (SEE) - that is, the standard error when attempting to estimate values for the dependent variable (for example, medial tibia) from the independent variable (such as ankle cartilage) in the regression-was $0.43 \mathrm{ml}(19 \%)$ for the distal tibial surface (ankle joint) $v$ medial tibial plateau (knee). The SEE was $0.40 \mathrm{ml}(18 \%)$ when using the proximal talar surface (ankle joint), $0.41 \mathrm{ml}(18 \%)$ when using the distal talar surface (subtalar joint), and $0.43 \mathrm{ml}(19 \%)$ when using the calcaneal surface (subtalar joint) to estimate values in the medial tibial plateau of the knee. These standard errors were relatively large compared with the standard deviation/ coefficient of variation ( $\mathrm{CV} \%$ ) of the cartilage volume in the medial tibia of healthy women $(0.37 \mathrm{ml} / 19 \%)$ and healthy men $(0.44 \mathrm{ml} / 16 \%)$, respectively.

The knee joint cartilage plates tended to display a slightly stronger correlation with MCSA of the thigh than with MCSA of the calf (table 3). However, the cartilage plates of the hind foot did not consistently show a stronger correlation with MCSA of the calf than with MCSA of the thigh (table 3).

Sex differences in cartilage morphology were greater for the joint surface areas (range, $-17.5 \%$ to $-23.5 \%$ ) than for the cartilage thickness (range, $+4.1 \%$ to $-19.5 \%$ ). Sex differences ranged from $-15.1 \%$ to $-31.8 \%$ for cartilage volumes of the knee, ankle, and subtalar joint surfaces, and did not show any obvious differences between joints (tables 4 and 5).

\section{DISCUSSION}

Our study is the first to provide a comprehensive analysis of the correlation of cartilage morphology between two different joints in the human body. We have specifically tested the 
Table 2 Average correlation coefficients ( $r$, Pearson) between joint surfaces of the knee, ankle, and subtalar joint

\begin{tabular}{llllll}
\hline Surfaces/joints & & $\begin{array}{l}\text { N coeff } \\
\text { averaged }\end{array}$ & Volume & Thickness & CJSA \\
\hline a) Knee & Knee & 6 & 0.77 & 0.68 & 0.75 \\
b) Ankle & Ankle & 1 & 0.81 & 0.87 & 0.74 \\
c) Subtalar & Subtalar & 1 & 0.95 & 0.74 & 0.93 \\
d) Hindfoot & Hindfoot & 6 & 0.81 & 0.63 & 0.78 \\
-) Knee & Ankle & 8 & $0.57(b-d)^{*}$ & $0.17(a-d)^{*}$ & $0.72(c)^{*}$ \\
-) Knee & Subtalar & 8 & $0.59(b-d)^{*}$ & $0.32(a-c)^{*}$ & $0.70(c)^{*}$ \\
-) Ankle & Subtalar & 4 & $0.78(c)^{*}$ & $0.54(a)^{*}$ & $0.76(c)^{*}$ \\
\hline
\end{tabular}

*Correlation coefficients significantly lower ( $p<0.05$, Fischer $z$ transformation) than those between cartilage plates of the same joint (compared with correlation coefficients in lines a to d).

CJSA, cartilaginous joint surface area $\left(\mathrm{cm}^{2}\right) ; \mathrm{N}$ coeff, number of correlation coefficients; thickness, mean cartilage thickness $(\mathrm{mm})$; volume, cartilage volume (ml).

hypotheses that cartilage loss in gonarthritis can be estimated retrospectively by quantitative magnetic resonance imaging of the ankle and knee, and that sex differences in cartilage morphology are greater in the knee than in the ankle, which may explain the higher prevalence of knee osteoarthritis in elderly women. State of the art MR imaging and digital analysis technology were used to investigate these relations in vivo in young, healthy subjects without signs of osteoarthritis. The MR sequence and analysis tools have been validated previously and tested for reproducibility in vivo. ${ }^{2} 15202829$ Precision errors are substantially less than the intersubject variability reported for healthy volunteers in both the knee and the hind foot; therefore the results of this study should not be critically affected by measurement errors.

A strong correlation between human knee and ankle cartilage morphology could not be confirmed by our study, although all subjects were healthy and none had any signs of joint disease. The subjects were carefully selected for young age and lack of any history of ankle or knee pathology (pain, trauma, or surgery). Moreover, to ensure that the subjects showed no signs of osteoarthritis, the MR images were rated by an experienced radiologist (CG) and an experienced orthopaedic surgeon (HG). The low correlation between cartilage morphology in the knee and ankle cannot thus be explained by the detection of incipient osteoarthritis in either the knee or ankle.

The correlation coefficients between cartilage volumes in the knee and ankle cartilage plates were not higher than those between cartilage volumes and body height, a variable that is clearly more easily measured. A recent paper has shown that, given the correlation with body height is only

Table 3 Correlation coefficients ( $r$, Pearson) between surfaces of the knee, ankle, and subtalar joint with muscle cross sectional areas of the thigh and calf, respectively

\begin{tabular}{llll}
\hline Joint & Variable & MCSA thight & MCSA calft \\
\hline Knee & Volume & $0.83^{* *}$ & $0.70^{* *}$ \\
& Thickness & $0.77^{* *}$ & $0.62^{*}$ \\
& SSA & $0.78^{* *}$ & $0.79^{* *}$ \\
\multirow{4}{*}{ Ankle } & Volume & $0.79^{* *}$ & $0.82^{* *}$ \\
& Thickness & $0.63^{* *}$ & $0.61^{*}$ \\
& JSA & $0.76^{* *}$ & $0.82^{* *}$ \\
\multirow{4}{*}{ Subtalar } & Volume & $0.79^{* *}$ & $0.75^{* *}$ \\
& Thickness & 0.48 & $0.53^{*}$ \\
& JSA & $0.77^{* *}$ & $0.72^{* *}$
\end{tabular}

${ }^{*} \mathrm{p}<0.05,{ }^{* *} \mathrm{p}<0.01$.

†Taken at $50 \%$ between the greater trochanter and the lateral joint space of the knee; łtaken at the maximum circumference.

JSA, joint surface area $\left(\mathrm{cm}^{2}\right)$; MCSA, muscle cross sectional area;

thickness, mean cartilage thickness (mm); volume, cartilage volume (ml).
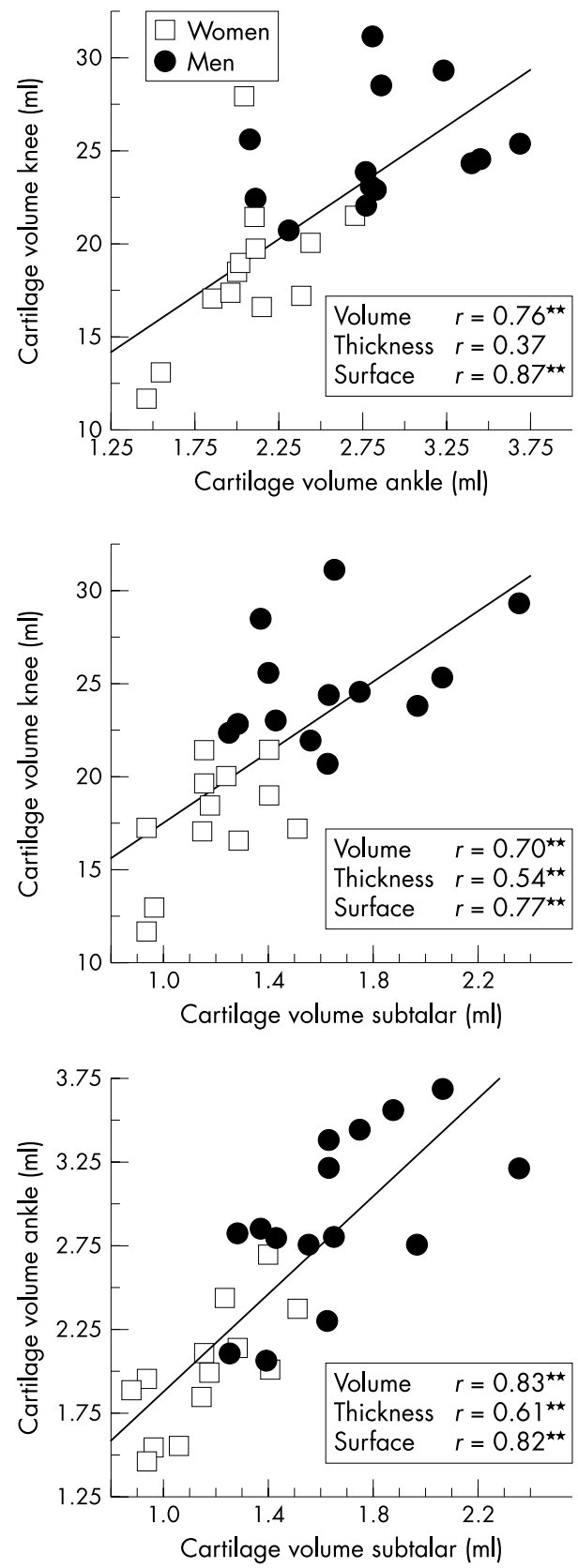

Figure 3 Bivariate scattergrams showing the correlation of cartilage volume in the knee, ankle, and subtalar joint. Women and men are identified in the graphs. Surface, joint surface area; thickness, mean cartilage thickness; volume, cartilage volume. 
Table 4 Sex differences of cartilage morphology in the knee joint

\begin{tabular}{|c|c|c|c|c|c|}
\hline Knee & Patella & Medial tibia & Lateral tibia & Femur & Total knee \\
\hline $\begin{array}{l}\text { Volume } \\
\text { Thickness } \\
\text { JSA }\end{array}$ & $\begin{array}{l}-15.1^{*} \\
+4.1 \\
-17.5^{\star * *}\end{array}$ & $\begin{array}{l}-29.3^{\star \star *} \\
-13.9^{\star *} \\
-20.6^{\star \star \star}\end{array}$ & $\begin{array}{l}-26.8^{* * *} \\
-7.5 \\
-23.0^{\star * *}\end{array}$ & $\begin{array}{l}-30.0^{* * *} \\
-19.5^{\star * *} \\
-21.2^{\star * *}\end{array}$ & $\begin{array}{l}-28.7^{* \star *} \\
-14.8^{\star *} \\
-20.9^{* * *}\end{array}$ \\
\hline
\end{tabular}

moderate, normalisation of knee cartilage volume to height does not improve the discrimination between healthy subjects and patients with knee osteoarthritis. However, normalisation to the original (cartilaginous + eroded) joint surface area (as measured from MR image data by digital image analysis) can substantially increase $t$ and $z$ scores for osteoarthritis patients. ${ }^{7}$ Not only did we find that the correlation coefficients between knee and ankle cartilage morphology in healthy subjects were moderate and not significantly greater than the correclation with body height, but in practice it would also be difficult to rule out convincingly the possibility that no quantitative change had occurred in ankle cartilage morphology.

The standard error of the estimate of the regression between the hind foot and knee joint surfaces and the standard deviation of knee joint cartilage volume among healthy men and women were in the same range. The correlation was thus not strong enough and the standard error of the estimate not sufficiently narrow to provide more precise estimates of cartilage loss in knee osteoarthritis beyond guesses based on the normal variability of cartilage morphology in reference subjects. The correlation coefficients between different joints for joint surface area and cartilage volume were somewhat higher than for cartilage thickness, probably because bone size is less variable throughout the body and (metaphyseal) bone size is the main determinant of cartilage surface area (and to a lesser degree also of cartilage volume).

One potential explanation for the heterogeneity of cartilage thickness between different joints is a concomitant heterogeneity between relevant muscle forces acting across the joints. We have shown previously that MCSAs of the thigh are significant predictors of knee joint cartilage morphology and provide additional information independent of body size and weight. ${ }^{10}$ For this reason we tested the hypotheses that there is a stronger correlation between knee joint cartilage thickness and thigh MCSA and between ankle and subtalar joint cartilage thickness and calf MCSA than the converse relations. This would imply that the heterogeneity in regional muscle forces is responsible for the heterogeneity in cartilage morphology between different joints. This hypothesis was, however, falsified. It thus remains unclear which factors cause one joint surface to have a large and another a relatively small cartilage thickness within an individual.

Previous ex vivo studies have revealed fundamental biochemical and biomechanical differences between ankle and knee cartilage. ${ }^{30-33}$ There are claims that these differences may also be responsible for the greater prevalence of cartilage lesions (osteoarthritis) in the knee than in the ankle. ${ }^{32-34}$ We have previously observed that women have substantially smaller joint surface areas than men ${ }^{19}$; smaller joint surfaces potentially predispose women to larger mechanical stress on their knee joint surfaces. This, in turn, may lead to earlier and more severe damage to the cartilage and joint. Because women over the age of 50 have a higher prevalence of osteoarthritis in the knee, but men have a higher prevalence of osteoarthritis in the ankle, we tested the hypothesis that sex differences in ankle cartilage morphology are greater in the knee than in the hind foot. However, our findings show that the sex differences in the knee, ankle, and subtalar joints are similar. Sex differences in susceptibility to osteoarthritis between knee and ankle are therefore not readily explained by differences in joint surface areas. It has been suggested that hormonal factors may be associated with osteoarthritis in postmenopausal women. However, it is currently unclear whether women with hormone replacement therapy are less often affected by osteoarthritis, and how and why this mechanism should preferentially affect the knee. ${ }^{35} 36$

\section{Conclusions}

We find that there is only a weak to moderate correlation of cartilage morphology between joint surfaces of the knee and the hind foot. This weak correlation makes it impractical to estimate knee joint cartilage loss retrospectively in a cross sectional study by measuring ankle cartilage and applying a scaling factor from an established regression equation. The heterogeneity of cartilage morphology between joints is not explained by differences in the local loading environment as there is no greater correlation with the relevant muscles (thigh versus calf). Sex differences were found to be of similar magnitude in the knee, ankle, and subtalar joint. The existing data do not support the hypotheses that sex differences in osteoarthritis incidence between the knee and ankle can be explained by differences in joint or cartilage morphology. Given the weak correlation between knee and ankle cartilage morphology, retrospective estimates of cartilage loss in cross sectional study designs must continue to rely on comparisons with samples of sex matched young subjects or age matched healthy volunteers, preferably with normalisation of cartilage volume to the "original" (cartilaginous + eroded) bone cartilage interface area. ${ }^{7}$

Table 5 Sex differences of cartilage morphology in the ankle and subtalar joints

\begin{tabular}{|c|c|c|c|c|c|}
\hline \multirow[b]{2}{*}{ Hind foot } & \multicolumn{2}{|l|}{ Ankle joint } & \multicolumn{2}{|c|}{ Subtalar joint } & \multirow[b]{2}{*}{ Total hind foot } \\
\hline & Distal tibia & Proximal talus & Distal talus & Calcaneus & \\
\hline $\begin{array}{l}\text { Volume } \\
\text { Thickness } \\
\text { JSA }\end{array}$ & 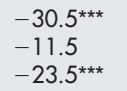 & $\begin{array}{l}-31.8^{\star * *} \\
-16.2^{\star *} \\
-21.7^{\star * *}\end{array}$ & $\begin{array}{l}-29.8^{* \star *} \\
-13.9^{\star *} \\
-21.9^{* \star *}\end{array}$ & 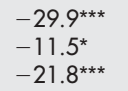 & $\begin{array}{l}-30.7^{* * *} \\
-12.5^{\star} \\
-22.2^{\text {***}}\end{array}$ \\
\hline
\end{tabular}




\section{ACKNOWLEDGEMENTS}

We thank Annette Thebis for her important help with data segmentation and Emily McWalter for editing the text. This study was supported by a grant from the German Research Foundation (DFG).

\section{Authors' affiliations}

V Siedek, D Al-Ali, Musculoskeletal Research Group, Institute of Anatomy, Ludwig-Maximilians-Universität München, Munich, Germany

F Eckstein, Institute of Anatomy, Paracelsus Medizinische

Privatuniversität, Salzburg, Austria

C Glaser, M Reiser, Institute for Clinical Radiology, Ludwig-MaximiliansUniversität München

K-H Englmeier, Institute for Medical Informatics and System Research (MEDIS), GSF Forschungszentrum für Umwelt und Gesundheit, Neuherberg, Germany

H Graichen, Department of Orthopaedics, University of Frankfurt, Frankfurt, Germany

\section{REFERENCES}

1 Peterfy CG. Imaging of the disease process. Curr Opin Rheumatol 2002;14:590-6.

2 Burgkart R, Glaser C, Hyhlik-Durr A, Englmeier KH, Reiser M, Eckstein F. Magnetic resonance imaging-based assessment of cartilage loss in severe osteoarthritis: accuracy, precision, and diagnostic value. Arthritis Rheum 2001;44:2072-7.

3 Wluka AE, Stuckey S, Snaddon J, Cicuttini FM. The determinants of change in tibial cartilage volume in osteoarthritic knees. Arthritis Rheum 2002;46:2065-72.

4 Cicuttini F, Wluka A, Wang Y, Stuckey S. The determinants of change in patella cartilage volume in osteoarthritic knees. J Rheumatol 2002;29:2615-19.

5 Gandy SJ, Dieppe PA, Keen MC, Maciewicz RA, Watt I, Waterton JC. No loss of cartilage volume over three years in patients with knee osteoarthritis as assessed by magnetic resonance imaging. Osteoarthritis Cartilage 2002:10:929-37.

6 Cicuttini FM, Wluka AE, Forbes A, Wolfe R. Comparison of tibial cartilage volume and radiologic grade of the tibiofemoral joint. Arthritis Rheum 2003;48:682-8.

7 Burgkart R, Glaser C, Hinterwimmer S, Hudelmaier M, Englmeier $\mathrm{KH}$, Reiser $M$, et al. Feasibility of $T$ and $Z$ scores from magnetic resonance imaging data for quantification of cartilage loss in osteoarthritis. Arthritis Rheum 2003;48:2829-35.

8 Eckstein F, Winzheimer M, Hohe J, Englmeier KH, Reiser M. Interindividual variability and correlation among morphological parameters of knee joint cartilage plates: analysis with three-dimensional MR imaging. Osteoarthritis Cartilage $2001 ; 9: 101-11$

9 Hudelmaier M, Glaser C, Hohe J, Englmeier KH, Reiser M, Putz R, et al. Agerelated changes in the morphology and deformational behavior of knee joint cartilage. Arthritis Rheum 2001;44:2556-61

10 Hudelmaier M, Glaser C, Englmeier KH, Reiser M, Putz R, Eckstein F. Correlation of knee-joint cartilage morphology with muscle cross-sectional areas vs. anthropometric variables. Anat Rec 2003;270A:175-84.

11 Eckstein F, Muller S, Faber SC, Englmeier KH, Reiser M, Putz R. Side differences of knee joint cartilage volume, thickness, and surface area, and correlation with lower limb dominance-an MRI-based study. Osteoarthritis Cartilage 2002;10:914-21.

12 Heine J. Über die Arthritis deformans. Arch Path Anat 1926;260:521-610.

13 Huch K, Kuettner KE, Dieppe P. Osteoarthritis in ankle and knee joints. Semin Arthritis Rheum 1997;26:667-74.

14 Koepp H, Eger W, Muehleman C, Valdellon A, Buckwalter JA, Kuettner KE, et al. Prevalence of articular cartilage degeneration in the ankle and knee joints of human organ donors. J Orthop Sci 1999:4:407-12.

15 Al Ali D, Graichen H, Faber S, Englmeier KH, Reiser M, Eckstein F. Quantitative cartilage imaging of the human hind foot: precision and intersubject variability. J Orthop Res 2002;20:249-56.
16 Felson DT, Zhang Y, Hannan MT, Naimark A, Weissman BN, Aliabadi P et al. The incidence and natural history of knee osteoarthritis in the elderly. The Framingham Osteoarthritis Study. Arthritis Rheum 1995:38:1500-5.

17 Jones G, Glisson M, Hynes K, Cicuttini F. Sex and site differences in cartilage development: a possible explanation for variations in knee osteoarthritis in later life. Arthritis Rheum 2000;43:2543-9.

18 Jones G, Ding C, Glisson M, Hynes K, Ma D, Cicuttini F. Knee articular cartilage development in children: a longitudinal study of the effect of sex, growth, body composition, and physical activity. Pediatr Res 2003;54:230-6.

19 Faber SC, Eckstein F, Lukasz S, Muhlbauer R, Hohe J, Englmeier KH, et al. Gender differences in knee joint cartilage thickness, volume and articular surface areas: assessment with quantitative three-dimensional MR imaging. Skeletal Radiol 2001:30:144-50.

20 Glaser C, Faber S, Eckstein F, Fischer H, Springer V, Heudorfer L, et al. Optimization and validation of a rapid high-resolution T1-w 3D FLASH water excitation MRI sequence for the quantitative assessment of articular cartilage volume and thickness. Magn Reson Imaging 2001;19:177-85.

21 Graichen H, von Eisenhart-Rothe R, Vogl T, Englmeier KH, Eckstein F. Quantitative assessment of cartilage status in osteoarthritis with qMRI: technical validation for use in analysis of cartilage volume and further morphologic parameters. Arthritis Rheum 2004;50:811-16.

22 Graichen H, Springer V, Flaman T, Stammberger T, Glaser C, Englmeier KH, et al. Validation of high-resolution water-excitation magnetic resonance imaging for quantitative assessment of thin cartilage layers. Osteoarthritis Cartilage 2000;8:106-14.

23 Graichen H, Jakob J, Eisenhart-Rothe R, Englmeier KH, Reiser M, Eckstein F. Validation of cartilage volume and thickness measurements in the human shoulder with quantitative magnetic resonance imaging. Osteoarthritis Cartilage 2003;11:475-82.

24 Stammberger T, Eckstein F, Michaelis M, Englmeier KH, Reiser M. Interobserver reproducibility of quantitative cartilage measurements: comparison of B-spline snakes and manual segmentation. Magn Reson Imaging 1999;17:1033-42.

25 Eckstein F, Gavazzeni A, Sittek H, Haubner M, Losch A, Milz S, et al. Determination of knee joint cartilage thickness using three-dimensional magnetic resonance chondro-crassometry (3D MR-CCM). Magn Reson Med 1996;36:256-65

26 Hohe J, Ateshian G, Reiser M, Englmeier KH, Eckstein F. Surface size, curvature analysis, and assessment of knee joint incongruity with MRI in vivo. Magn Reson Med 2002;47:554-61.

27 Stammberger T, Eckstein F, Englmeier KH, Reiser M. Determination of 3D cartilage thickness data from MR imaging: computational method and reproducibility in the living. Magn Reson Med 1999:41:529-36.

28 Eckstein F, Heudorfer L, Faber SC, Burgkart R, Englmeier KH, Reiser M. Longterm and resegmentation precision of quantitative cartilage $M R$ imaging (qMRI). Osteoarthritis Cartilage 2002;10:922-8.

29 Hohe J, Faber S, Muehlbauer R, Reiser M, Englmeier KH, Eckstein F. Threedimensional analysis and visualization of regional MR signal intensity distribution of articular cartilage. Med Eng Phys 2002;24:219-27.

30 Treppo S, Koepp H, Quan EC, Cole AA, Kuettner KE, Grodzinsky AJ. Comparison of biomechanical and biochemical properties of cartilage from human knee and ankle pairs. J Orthop Res 2000;18:739-48.

31 Huch K. Knee and ankle: human joints with different susceptibility to osteoarthritis reveal different cartilage cellularity and matrix synthesis in vitro. Arch Orthop Trauma Surg 2001;121:301-6.

32 Kerin A, Patwari P, Kuettner K, Cole A, Grodzinsky A. Molecular basis of osteoarthritis: biomechanical aspects. Cell Mol Life Sci 2002;59:27-35.

33 Eger W, Schumacher BL, Mollenhauer J, Kuettner KE, Cole AA. Human knee and ankle cartilage explants: catabolic differences. J Orthop Res 2002:20:526-34

34 Kang Y, Koepp H, Cole AA, Kuettner KE, Homandberg GA. Cultured human ankle and knee cartilage differ in susceptibility to damage mediated by fibronectin fragments. J Orthop Res 1998;16:551-6.

35 Von Muhlen D, Morton D, Von Muhlen CA, Barrett-Connor E. Postmenopausal estrogen and increased risk of clinical osteoarthritis at the hip, hand, and knee in older women. J Womens Health Gend Based Med 2002;11:511-18.

36 Nevitt MC, Felson DT, Williams EN, Grady D. The effect of estrogen plus progestin on knee symptoms and related disability in postmenopausal women: the Heart and Estrogen/Progestin Replacement Study, a randomized, doubleblind, placebo-controlled trial. Arthritis Rheum 2001;44:811-18. 